
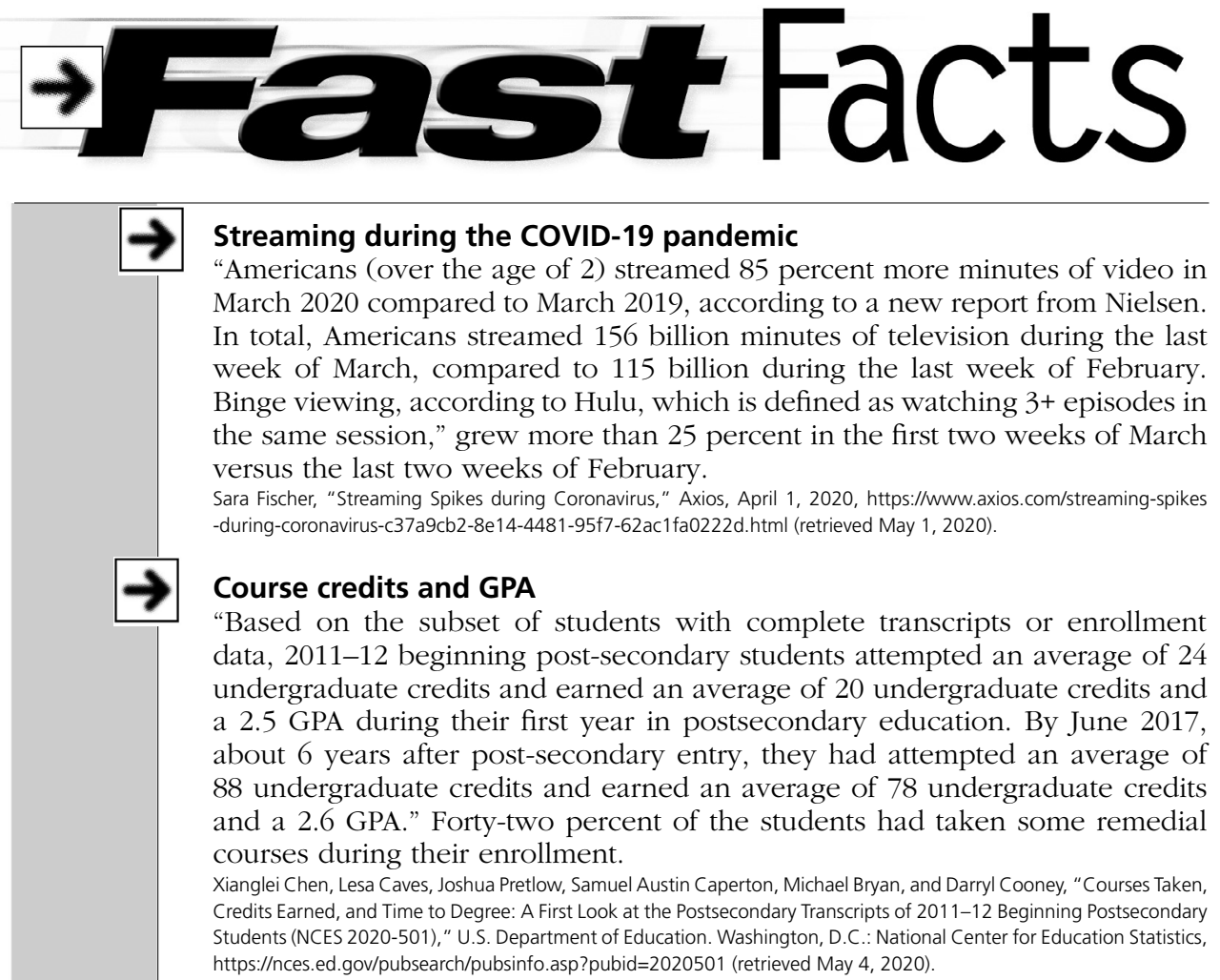

\title{
Podcasts
}

The top three podcast publishers as of March 2020 are NPR, iHeartRadio, and New York Times, accounting for 61,718,000 monthly listeners in the United States and 549,689,000 global downloads and streams monthly.

Podtrac, Inc., "Top Podcast Publishers-US Audience: March 2020," http://analytics.podtrac.com/podcast-publisher -rankings (retrieved May 5, 2020).

\section{Educational institutions}

In 2017, there were 98,158 public K-12 schools and 32,461 private K-12 schools in the United States. There were 2,407 four-year colleges. Of those, 711 were public institutions and 1,301 were private-nonprofit institutions. The remainder were private for-profit institutions.

U.S. Department of Education, National Center for Education Statistics, "Digest of Education Statistics, 2018 (NCES 2020-009)," https://nces.ed.gov/programs/digest/d18/ch_2.asp (retrieved May 5, 2020), and U.S. Department of Education, National Center for Education Statistics, "The Condition of Education - Postsecondary Education - Postsecondary Institutions - Characteristics of Degree-Granting Postsecondary Institutions - Indicator May (2019), " https://nces.ed.gov /programs/coe/indicator_csa.asp (retrieved May 5, 2020).

\section{Facebook}

"With over 2.6 billion monthly active users as of the first quarter of 2020 , Facebook is the biggest social network worldwide. During the last reported quarter, the company stated that almost 3 billion people were using at least one of the company's core products (Facebook, WhatsApp, Instagram, or Messenger) each month."

J. Clement, "Facebook Users Worldwide 2019," Statista, https://www.statista.com/statistics/264810/number-of -monthly-active-facebook-users-worldwide (retrieved May 5, 2020).

Gary Pattillo is reference librarian at the University of North Carolina-Chapel Hill, e-mail: pattillo@ email.unc.edu 